\title{
Generic drug prescribing in primary care: a nationwide analysis
}

\author{
Dilara Bayram ${ }^{1}$, Volkan Aydin ${ }^{1}$, Ayşe Gelal ${ }^{2}$, Mesil Aksoy $^{3}$, and Ahmet Akici ${ }^{4}$ \\ ${ }^{1}$ Marmara Universitesi \\ ${ }^{2}$ Dokuz Eylul Universitesi Tip Fakultesi \\ ${ }^{3}$ Türkiye İlaç ve Tibbi Cihaz Kurumu \\ ${ }^{4}$ Affiliation not available
}

September 28, 2020

\begin{abstract}
Purpose: Dissemination of generic drug (GD) use could provide significant savings on drug expenditures and contribute to the long-term sustainability of healthcare. We aimed to exhibit the nationwide trend of GD use in primary care and investigate potentially relevant drug and patient factors. Methods: We analyzed all electronic prescriptions registered to national Prescription Information System by primary care physicians in Turkey during 2013-2016. We determined GD share in quantity and cost for each year. We further analyzed GD use in terms of patients' demographic characteristics, most commonly prescribed preparations, and frequent indications. Results: In the four-year period, we identified 518,335,821 prescriptions, where GDs constituted $54.0 \%(\mathrm{n}=786,972,813)$ with a total cost share of $36.9-37.8 \%$. GD use was highest in $2016(54.4 \%)$ and lowest in 2014 (53.6\%). In each year, GD prescribing was higher in women $(53.7-54.7 \%)$ than men $(53.4-54.1 \%, \mathrm{p}<0.001)$. GD utilization decreased as the age group increased, which was $64.0-64.5 \%$ in $<18$-year-old group and $46.0-47.1 \%$ in [?]75-year-old group. Among the top ten encountered indications, highest and lowest GD prescribing was detected in acute tonsillitis (68.1\%) and hypertension (33.9). Metformin had the highest percentage of GD prescribing (96.1-97.7\%) whereas esomeprazole showed the lowest GD prescribing (4.5-14.8\%) among the most frequently used preparations in primary care. Conclusions: This study shows a modest upward trend of GD utilization in primary care, though its share appears as lower than expected. GDs were less likely to be prescribed in older age groups and seem as more pronounced in acute conditions, particularly infectious diseases.
\end{abstract}

\section{Generic drug prescribing in primary care: a nationwide analysis}

\section{Generic drug prescribing in primary care}

Dilara Bayram ${ }^{1}$, Volkan Aydin ${ }^{1}$, Ayse Gelal ${ }^{2}$, Mesil Aksoy $^{3}$, Ahmet Akici ${ }^{1}$

1. Department of Medical Pharmacology, Marmara University School of Medicine, Istanbul, Turkey.

2. Department of Medical Pharmacology, Dokuz Eylul University School of Medicine, Izmir, Turkey

3. Turkish Medicines and Medical Devices Agency, Ministry of Health, Ankara, Turkey.

\section{Corresponding Author:}

Prof. Dr. Ahmet Akici, Marmara University Faculty of Medicine, Department of Medical Pharmacology, Istanbul, Turkey. E-mail: aakici@marmara.edu.tr

Ethics Statement: The study was approved by Ethics Committee for Non-interventional Studies of Dokuz Eylul University (Approval No: 2019/05-32).

Conflict of interest: The authors declare that there is no conflict of interest.

Funding information: The authors received no specific funding for this work. 
Data availability statement: The data that support the findings of this study are available from thecorresponding author upon reasonable request.

An author contribution statement : Conception and design: AA, DB, VA, AG; Acquisition of data: DB, MA, AA; Analysis and interpretation of data: DB, VA, AG, AA; Been involved in drafting the manuscript or revising it critically for important intellectual content: DB, VA, AG, MA, AA; Given final approval of the version to be published: DB, VA, AG, MA, AA.

\section{What is already known about this subject}

- Generic drugs have generally lower costs than reference drugs and provides significant savings on healthcare costs.

- Generic drug utilization varies widely between countries and affected by many factors, including demographic and clinical features of patients.

\section{What this study adds}

In Turkey, generic drugs had a share of $54 \%$ in quantity and $37 \%$ in cost.

- Generic drug prescribing was decreased as the age group increased, which was lowest in [?]75-year-old group.

- Generic drugs seem as more pronounced in acute conditions, particularly infectious diseases.

\section{Clinical significance}

The findings in our study emphasize that one of the prioritized addresses of activities to promote generic drug use is primary care physicians.

\section{Hosted file}

Generic drug use in primary care.pdf available at https://authorea.com/users/362158/articles/ 483389-generic-drug-prescribing-in-primary-care-a-nationwide-analysis

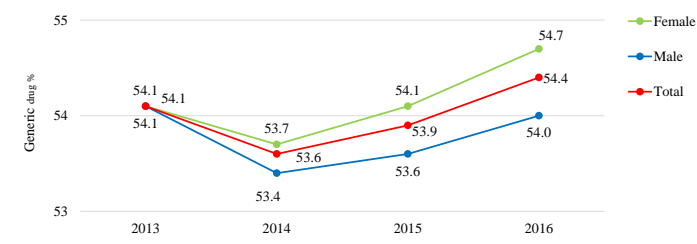



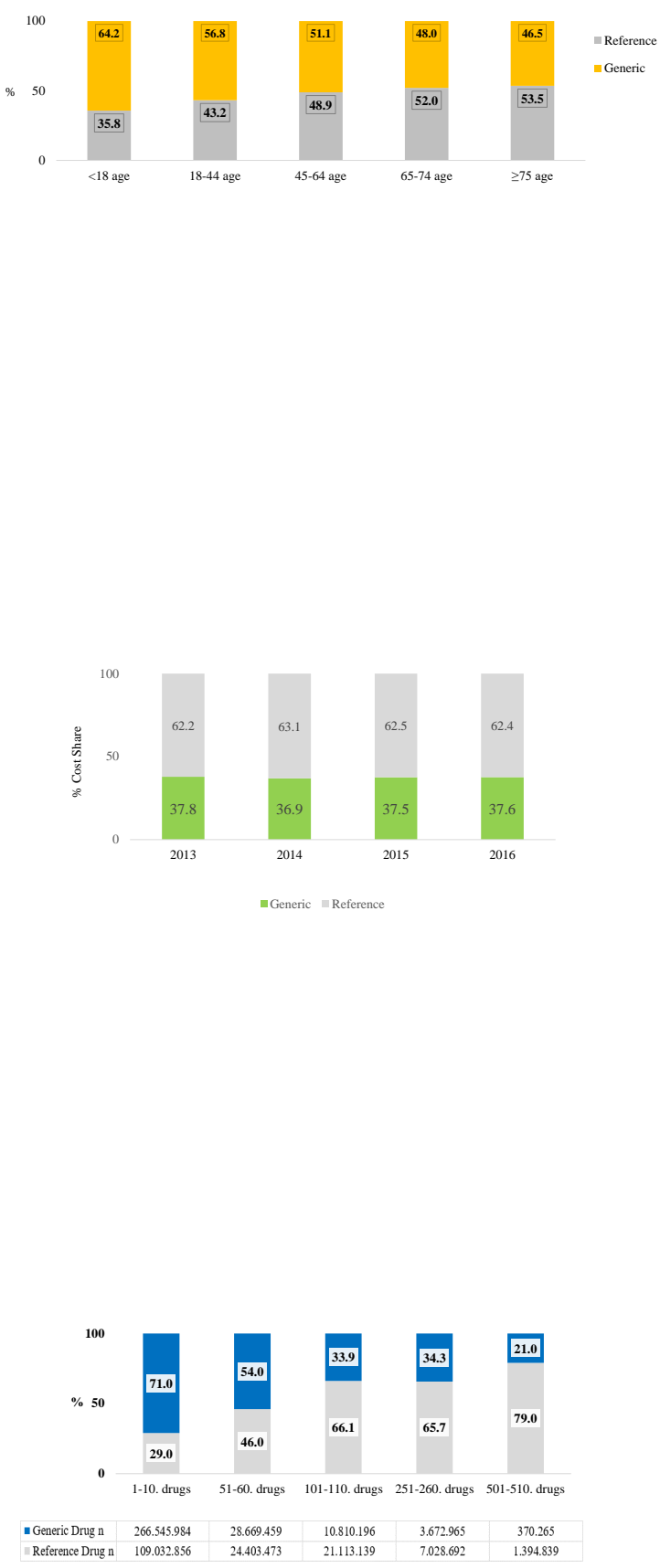


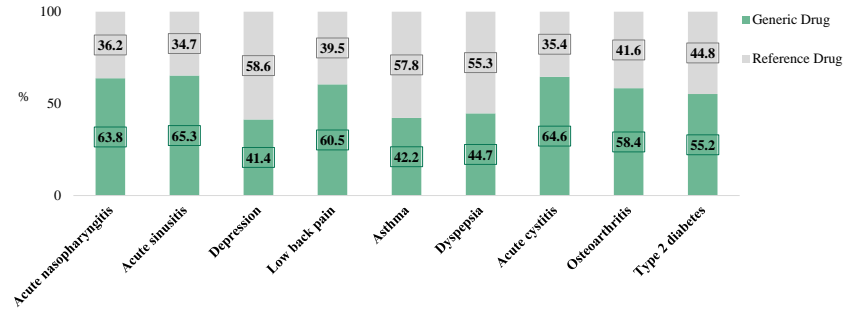

